Note: This is a pre-print and has not undergone peer review.

\title{
Community-Based Research: Perspectives of Psychology Researchers and Community Partners
}

Nicole Racine ${ }^{1}$, Ph.D., R.Psych., Sheri Madigan ${ }^{1}$, Ph.D., R.Psych, Shelley Cardinal², M.A., Cailey Hartwick ${ }^{3}$, Ph.D., R.Psych., Margaret Leslie ${ }^{4}$, Dip.C.S. C.Psych.Assoc., Mary Motz ${ }^{4}$, Ph.D., C.Psych., Debra Pepler ${ }^{5}$, Ph.D., C.Psych.

Affiliations: ${ }^{1}$ Department of Psychology, University of Calgary, Calgary, Alberta, Canada;

${ }^{2}$ Canadian Red Cross Society, Victoria, British Columbia, Canada; ${ }^{3}$ Child Abuse Service, Alberta Children's Hospital, Calgary, Alberta, Canada; ${ }^{4}$ Mothercraft/Breaking the Cycle, Toronto, Ontario, Canada; ${ }^{5}$ Department of Psychology, York University, Toronto, Ontario, Canada.

Short title: Community-based research in Canada

Tables $=2$

Figures $=0$

Author Note

We have no known conflict of interest to disclose.

Acknowledgments: We would like to thank the staff at Breaking the Cycle, the Child Abuse Service, and the Canadian Red Cross for engaging in community-based research with us. We are also grateful to the children, youth, and families who have participated in our research through these community organizations.

Address correspondence to: Nicole Racine, Ph.D., R.Psych, Department of Psychology University of Calgary, Calgary, AB, T2N 1N4, Canada, Phone: 403-992-7869; Email: nicole.racine2@ucalgary.ca 


\begin{abstract}
There is now a growing understanding that translational research must be co-created in collaboration with community partners and that solutions to real-world social problems require stepping outside the academic silo. Fewer than half of psychology programs in Canada, however, offer courses in community-based research or evaluation, leaving a gap in skill development amongst the next generation of scholars. In an effort to partially fill this learning gap, the current paper provides insights into lessons learned from the perspectives of researchers and community partners alike, who have been mutually engaging in community-based research over the last 25 years. Ultimately this paper seeks to provide a roadmap for conducting community-based research and illustrates why it should be a central component to research seeking to answer critical questions in psychological science. First, we provide a conceptual foundation of community-based research. Next, using three specific community-based research projects as examples, we share the challenges and benefits of conducting research in the community context. Finally, we highlight future directions for increasing the uptake of community-based research in Canada.

Keywords: community-based research, evaluation, community partners, researchers, psychology
\end{abstract}

Public Significance Statement: From the perspectives of researchers and community partners who have been co-creating research, we provide lessons to approach these research partnerships. We discuss challenges, successes, and future directions for community-based research in Canadian psychology. 


\section{Community-Based Research: Perspectives of Psychology Researchers and Community Partners}

The mental health challenges of Canadians across the life course is one of the most significant social problems of our time (Smetanin et al., 2011). With training in psychological mechanisms, research methods, statistics, interaction skills, and systems thinking, psychologists are well-positioned to be at the forefront of addressing and generating solutions to this complex social problem. Finding innovative, real-world solutions necessitates stepping outside the academic silo to engage with community partners for meaningful impact (Skipper \& Pepler, 2020). That is, partnerships between researchers in psychology and community organizations are essential for addressing complex, real-world problems. Community-based research refers to research that is conducted in collaboration with a community partner in a community setting. Increasingly, the need for community-based research is being recognized in the strategic research plans of Canadian universities, as well as in research grant bodies. Thus, there is a growing understanding that for research to be translational, it must be conceived and co-created with stakeholders at the outset.

Although the perceived importance of community-engaged research is growing, a training gap remains: only a minority of psychology programs in Canada offer undergraduate and graduate student training in community psychology, community-based research, or program evaluation (Aubry et al., 2010). Community-engaged research requires different methods and approaches than research conducted in the traditional university laboratory setting. Thus, students and scholars interested in engaging in community-based research can find themselves somewhat adrift, wanting to engage with community partners, but feeling uncertain as to how to initiate and navigate partnerships, which can increase risk for short-lived, superficial, or even 
harmful partnerships (Koster et al., 2012). Similarly, it can be challenging for community agencies to know how to or who to engage from the research community when they are interested in co-creating research initiatives.

Although community-engaged research in psychology has a long history in Canada, there is a timely interest and need to revisit its critical theories and components, particularly for subdisciplines within psychology where the concepts are less familiar. Based on our collective experiences of conducting community-based research, we describe the conceptual foundations and contemporary developments, as well as lessons learned from both the perspectives of researchers and community partners who have been engaging in community-based research over the last 25 years. This paper has been intentionally co-written by researchers and community partners who have engaged in community-based research together. First, we describe why it is essential to engage in community-based research and provide a brief overview of its main components. Next, from the perspective of researchers ranging in career stages at different academic institutions and partners at three community agencies (Breaking the Cycle, the Canadian Red Cross, and the Child Abuse Service), we discuss some of the critical ingredients for establishing and conducting mutually beneficial community research projects. Finally, we discuss some of the challenges, benefits, and future directions for conducting community-based psychological research in Canada.

\section{Why Conduct Community-Engaged Research}

Psychologists have made immense headway over the last 50 years in creating and establishing evidence-based interventions to address various mental health difficulties across the lifespan (McHugh \& Barlow, 2012). Despite these efforts, a significant gap remains in integrating this knowledge into clinical contexts and practice (Kazdin, 2016). One reason for this 
knowledge-to-practice gap may be the ineffective nature of the unidirectional knowledge flow from the "developers" (i.e., researchers) of the interventions to the "knowledge users" (i.e., clinicians or community agencies) who are expected to apply the knowledge. Specifically, interventions developed using a "top-down approach" in highly controlled environments with specific populations (e.g., Randomized Control Trials in laboratory settings) may fail to accommodate many practical considerations in implementing these interventions in a clinical or community setting (Kazdin, 2016). Additionally, many community mental health organizations lack the time, resources, and expertise to conduct rigorous program evaluation (Minden, 2021). Given these challenges, researchers must work collaboratively with community partners to cocreate knowledge and interventions that have the potential to improve mental health (Craig et al., 2021).

\section{What is Community-Based Research?}

Community-based participatory research (CBPR) is a type of community-engaged research founded on developing relationships with community partners who are actively involved in the research process and benefit directly from the outputs (Hacker, 2013; Wallerstein \& Duran, 2006). In contrast to traditional approaches that favour researcher-driven questions and methods, CBPR involves conducting research "with community partners rather than on community partners" (Koster et al., 2012). In CBPR, community members and organizations are respected and valued as full partners in the research process, and knowledge is acquired, analyzed, and disseminated in a collaborative way that mutually benefits both the researcher and the community partners' policies and practices (Hacker, 2013; Pepler, 2016; Skipper \& Pepler, 2020). Although the community partner benefits from the research capacity that the researchers bring, it is critical to acknowledge the bi-directional nature of the research relationship. That is, 
researchers stand to benefit immensely from the community partner's local knowledge, experience, interpersonal relationships, expertise, and existing relationships with populations that would be otherwise difficult for researchers to reach (Corburn, 2005). In our experience, researchers benefit most in the collaborative relationships formed, and ideas generated, particularly regarding new ways of thinking and knowing in research with specific populations that are only accessible through partnerships.

In the context of conducting research with children's mental health agencies and organizations, Craig and colleagues have proposed a theoretical model, the DevelopmentalRelational Model of Research Co-Creation, as a guide for academic researchers to engage in beneficial and effective relationships with community partners (2021). A "developmental approach" to research refers to the fact that it is critical for researchers to consider their own readiness, as well as the readiness of their partner, prior to engaging in research. A "relational approach" to research refers to creating positive, collaborative, and long-term relationships with community partners through relationship building and shared understanding. Within this theoretical model, the authors delineate a three-step process through which researchers can undertake projects that are both "developmental" and "relational" in nature, including building a relationship, conducting the research, and mobilizing the knowledge for change. The Developmental-Relational Model of Research Co-Creation has been a central pillar in guiding our own processes when engaging in community-based research.

\section{Community-Based Research Partnerships}

To contextualize the lessons learned, challenges, and future directions of conducting community-based research, we describe the contexts in which our community-based research collaborations have occurred. We note at the outset that most of our learning occurred in the field 
and through experience, rather than through knowledge or expertise gained in a formal learning environment. Our experiences engaging in community-based research involved steep learning curves and it is only in hindsight that we can look back and share what we have learned. The emerging (Racine) and mid-career researchers (Madigan, Motz) involved in this project benefitted immensely from the mentorship and guidance of a senior researcher (Pepler) who has been engaging in community-based research for more than 35 years. Thus, an important goal of the current paper is to share this knowledge with others in order to support the creation of mutually beneficial community-based research partnerships.

The organizations we have engaged in research partnerships span from local community agencies (i.e., Breaking the Cycle and the Child Abuse Service) to a national organization (the Canadian Red Cross). They also span geographic locations across Canada, including urban and rural/remote settings. All three organizations are concerned with children's and families' mental health and well-being, with an emphasis on promoting healthy child development and relationships. These research partnerships also range developmentally from a well-established partnership that has existed for more than 25 years (i.e., Breaking the Cycle) to a partnership established in the last five years (i.e., the Child Abuse Service). Lastly, we describe partnerships that were established at the outset of a program's development and research partnerships that formed within mature organizations. Taken together, by providing examples of diverse collaborations, we hope to provide lessons and examples that will be relevant in various community settings.

\section{Breaking the Cycle, Canadian Mothercraft Society}

Breaking the Cycle (BTC) is an early prevention and intervention program in Toronto, Canada, for substance-involved pregnant women and women parenting children under six years 
of age. Established in 1995 by the Canadian Mothercraft Society, BTC's overarching goal is to enhance the development of substance-exposed children through services that address maternal substance use difficulties and the mother-child relationship. A concurrent goal is to address challenges with the fragmented delivery of services that substance-involved pregnant or parenting women receive across the adult and child-service sectors. Prior to BTC, substanceinvolved pregnant and parenting women often faced multiple intake experiences, a lack of consistency in providers, service delivery in multiple locations, and poor communication and coordination among providers.

Using a community-based, cross-systemic model, families at BTC receive a wide range of services, including addictions counselling, health/medical services, parenting intervention, developmental screening and assessment, child-care, early childhood interventions, basic needs support, and interpersonal violence interventions. All of its services are delivered through a partnership model, including the health, mental health, corrections, child welfare, and children's services sectors (Motz et al., 2006; Pepler et al., 2014). Using this approach, clients can access various services in one location, which reduces barriers to service access. A home visitation component, and street outreach for pregnant women, complement the single access model. BTC has received several recognitions for its exemplary service delivery, including the United Nations Office on Drugs and Crime and awards from the Kaiser Foundation for excellence in mental health and substance use programming.

Breaking the Cycle is unique in that research was embedded within the clinical services from its inception. BTC's funder, the Public Health Agency of Canada (then Health Canada), required evaluation to be embedded in the initial proposal for funding. Mothercraft engaged researchers from York University with whom they had partnered on previous research. BTC has 
since developed its own research program and expertise that have led to numerous evaluation reports (Motz et al., 2006; Pepler et al., 2002), scholarly research outputs (e.g., (Andrews et al., 2018; Espinet et al., 2016; Motz et al., 2019), and the national dissemination of BTC's interpersonal violence intervention and theoretical approaches and frameworks (Mothercraft Press, 2014).

Over the last 25 years, the researchers engaged in collaboration with BTC have learned to "walk beside" the BTC staff and clients to develop a research program that is both rigorous and impactful (Skipper \& Pepler, 2020). An essential aspect of the success of this partnership was the role of an embedded evaluation researcher (Motz), who held the positions of both clinician and researcher. This allowed for the acceptability and ease of implementation of research with both staff and clients. Following successful program evaluation, BTC and collaborating researchers successfully received funding from the Canadian Institutes of Health Research for a longitudinal study to compare BTC to another treatment program for mothers with addictions (Espinet et al., 2016). The research capacity of the program has substantially expanded to include the dissemination and evaluation of BTC's interpersonal violence intervention (Andrews et al., 2021) and the neurodevelopmental sequelae of children exposed prenatally to substances (Bondi et al., 2020). The community-based research collaboration at BTC has provided an opportunity to study the mechanisms and processes by which early intervention exerts its effects on child development, as well as a platform to disseminate these findings locally, nationally, and internationally.

\section{Child Abuse Service, Luna Child and Youth Advocacy Center}

Over the last 20 years, the Child Abuse Service (CAS) at the Alberta Children's Hospital has provided mental health services to the most urgent and severe cases of child sexual abuse, 
physical abuse, and neglect in Southern Alberta. The CAS is an outpatient specialty clinic funded by Alberta Health Services comprising psychologists, social workers, and mental health therapists who identify and address the impact of child abuse and support children in need of healing from trauma. In 2013, the CAS joined the Luna Child and Youth Advocacy Centre (previously the Calgary and Area Child Advocacy Centre) as a partner agency. The Luna Center is a non-profit organization funded by the federal Department of Justice, which addresses child abuse through a partnership model. Partners of the Luna Centre include the provincial health authority, local police services, the justice department, child welfare, and the federal police services, who all work to provide wrap-around services to assess, investigate, intervene, and treat children who have experienced abuse. As one of the largest and most well-established child abuse programs in Canada, the CAS was well-positioned to be a national and international leader in the creation, evaluation, and dissemination of the best available evidence for treating childhood trauma and PTSD. The CAS had identified their lack of capacity, resources, and infrastructure to implement a comprehensive and robust research program as a significant barrier to capitalizing on this opportunity. Thus, a collaborative research partnership with researchers at the University of Calgary (Madigan and Racine) was established with the CAS as a mutually beneficial endeavour.

Since the program had already been in operation for 20 years, the development of trusting relationships and consultation were critical to establishing a cohesive partnership. This took the form of multiple meetings and brainstorming sessions with all staff to develop partner-driven research goals and directions. First, the CAS team wanted to understand the characteristics and service needs of their population. Second, the CAS team wanted to know which clients were benefitting from clinical services within the CAS by examining predictors of treatment 
completion and drop-out (Eirich et al., 2020) and whether protective factors helped reduce trauma symptoms (Racine, Eirich, et al., 2020). To address these questions, we embarked on a retrospective file review (Racine et al., 2021), which is a comprehensive and non-invasive approach to obtaining detailed information within a community organization (Gearing et al., 2006). We were successful in obtaining a Partnership Engage Grant from the Social Sciences and Humanities Research Council to fund this initial stage of the research. Research design and methods were initially developed and shared with the clinical team, who then provided feedback that was integrated into a finalized research project plan. Building on the success of answering these research questions, the CAS and the researchers have successfully obtained a three-year grant to formally evaluate treatment outcomes of children receiving services at the CAS. Findings from this research collaboration have been shared locally, nationally, and internationally through workshops, conference presentations, presentations to community groups, and publications (e.g., (Eirich et al., 2020; Racine et al., 2021; Racine, Eirich, et al., 2020; Racine, Hartwick, et al., 2020)

\section{The Canadian Red Cross Society}

The Canadian Red Cross Society is a charitable and humanitarian organization whose mandate is to support and strengthen resilience during times of need. Funded through donations, philanthropy, and government support, the Canadian Red Cross trains volunteers in emergency and disaster response, disaster assistance, injury prevention, and community education across the country. One priority area for the Canadian Red Cross has been violence and abuse prevention within Indigenous communities. Spearheaded by Shelley Cardinal, Director of Indigenous Relations for the Canadian Red Cross, Walking the Prevention Circle is a program that supports 
communities in creating safe environments for children and youth and promotes communitybased skills for preventing violence and abuse.

In 2003, Shelley Cardinal and Debra Pepler met at a violence prevention conference and their journey of co-creation began. They quickly recognized their mutual passion for supporting the wellbeing of children and youth and began to form a warm working relationship. They began to imagine how to evaluate the effectiveness of Walking the Prevention Circle, a program that Cardinal was implementing with communities across Canada. There was so much learning through the early stages on both sides to ensure we were ready to engage in this partnership research. Pepler needed to learn how to approach the research in communities in a culturally attuned way, leaving aside her standardized western psychology measures. Cardinal needed to gain trust in the research process, as so many Indigenous communities had been deeply harmed by researchers. We began our collaborative work by co-creating a funding application to the Canadian Institutes for Health Research, which was not successful. Looking back at the application, we recognize that it was misaligned in many ways, specifically with a focus on individual health, rather than Indigenous community wellbeing. With Alice Vaughan, a graduate student funded by MITACS, we conducted a preliminary evaluation of Walking the Prevention Circle, with existing data and a series of interviews in one community that had participated in Walking the Prevention Circle (Pepler \& Rubin-Vaughan, 2011). The community members indicated that the workshop had increased their understanding of child/youth abuse and harassment, as well as how to work with children and youth and handle disclosures of abuse.

With this groundwork, Pepler and Cardinal prepared a partnership application to the Social Sciences and Humanities Research Council, in collaboration with both Indigenous researchers and other partner organizations. The partnerships were critical because an essential 
component of Indigenous research methods is that the Indigenous community drives the nature, process, and sharing of the research findings. The application for funding was successful, but engaging the communities in the research proved difficult, due to a lack of trust arising from the harms that Indigenous communities had experienced through past research. To understand and address the communities' hesitation to partner in the research, we reflected on the specific ethics of engaging in research with diverse Indigenous Peoples (Riddell et al., 2017), as well as the decolonizing approach that is required in this research. We were committed to working with communities in a humble-relational way that was grounded in respect, open communication, understanding responsibility and accountability, and ensuring learning in all places.

We have learned so much from the communities through our research collaborations. First, they helped us understand the journey that they take to restore community health as they move away from the harms of colonization toward their landing place of wellness (Ricard et al., 2021). We were focused on understanding communities' journeys to re-establishing health as they transition from the cycle of violence to the circle of wellness. The knowledge shared by community members helped us recognize that every form of harm from colonization has created physical, mental, emotional, and spiritual violence, which has disrupted all domains of Indigenous wellbeing. We have developed a Starting Place Story as a self-determination tool for communities to gather their understanding of the cycle of violence from colonization experienced within the community, the vision of wellness for the community, and the pathways that they can follow to restore their cultural ways of being, doing, and knowing (Ricard et al., 2021).

All three community-based research partnerships described in the current paper have been successfully established and are ongoing. Each community-researcher partnership was 
established using the principles of a developmental-relational research process (described above). Through establishing research relationships, we have learned that a humble-relational and interdependent approach to conducting research is needed. This involves what Skipper and Pepler refer to as "orienting away" from the individual needs of the researcher towards interdependent collaboration to answer research questions that are of interest to the partner (2020). This process has ensured the longevity and sustainability of the partnership and enhanced the impact and uptake of the findings.

\section{Conducting Community-Based Psychological Research}

Step-by-step guides for conducting community-based research have been documented elsewhere (Craig et al., 2021; Hacker, 2013). Thus, based on our experiences, we highlight specific considerations and lessons within the Canadian psychology context from the perspective of researchers and community partners.

\section{Considerations for Researchers}

While community-based research is collaborative, relational, and mutually beneficial, researchers have expectations and demands within academia that stipulate the generation and dissemination of research knowledge. While we agree that the role of researchers extends far beyond the production of scholarly outputs (i.e., publications), we are realistic in acknowledging that the production of these outputs remains an essential determinant for meeting academic success criteria (Rawat \& Meena, 2014). Thus, researchers may find themselves balancing the community partners' needs and what is required to form a successful partnership with their own professional needs. For example, the researcher needs to use a relational approach and consider research feasibility, productivity, and rigor. At the outset of engaging in community-based research, the researcher must consider and reflect on whether the research team has or is willing 
to develop the appropriate relational capacities and whether the research partnership can feasibly meet the researcher's requirements for academic research. We present a series of questions that may be helpful to answer when considering engaging in a community-based research project (See Table 1). We expand on these questions and provide examples from our own experiences below.

\section{Is My Research Team Capable of Engaging in a Positive, Respectful, and Humble}

\section{Relationship with a Community Partner?}

Developing respectful, thoughtful, and positive relationships with individuals at all levels of the community partnership is critical for the unfolding and sustainability of the research process. Andrews and colleagues (2019) discuss the importance of a relational approach to community-based research, which involves the conscious and deliberate development of positive relationships at all levels of the research ecology, including "among researchers, between researchers and community partners, among community partners, between organizations and communities, and across systems" (p.552). In their research of the replication of Breaking the Cycle's trauma-informed interpersonal violence intervention and theoretical approaches in communities across Canada, Andrews and colleagues identified relational development as one of the most critical ingredients for engaging in community-based research. Indeed, in our own experience, we have learned that the development and promotion of healthy and productive relationships between the research team and community partners have been essential to building ongoing research programs and moving our projects forward. In our experiences working with community partners who provide services to traditionally marginalized groups, including maltreated families, substance-using mothers and their children, and First Nations communities, it was essential to establish a trusting relationship at the outset of our work together. The 
community partners needed to know that our work together would be humble (i.e., community partner as the expert of their experiences and field), transparent, respectful, and valuable to their organization. Indeed, flexibility, transparency, and relational prioritization have been identified as foundational components of successful research collaborations in other community-based research (Crooks et al., 2018). Researchers need to ask themselves, can I listen, follow the lead of the community partner, and be patient when barriers arise? A top-down or expert model will not be effective in developing a community partnership. Researchers will find slow or minimal progress in establishing a productive research partnership using this approach.

\section{Does the Community Partner Share Similar Relational Values?}

In addition to embodying a relational capacity themselves, researchers should seek out community partners who also value relationships. A successful research partnership cannot develop unless all parties involved are on board with a relational approach. For example, in our experience with each of the community partners we have worked with, there has been a genuine sense of respect and value in the research we are doing. This is not to say that all staff members embraced the research process wholeheartedly from the outset. Indeed, we have felt resistance at times to research implementation and the structural changes it may cause. However, we have worked strategically to overcome any actual or perceived barriers through active listening, selfreflection, and team discussions.

Seeking out community partners who ascribe to a relational approach and mindset will lead to a more successful partnership. It may also be challenging to forge a research collaboration with an organization that is not ready to include research as part of its practice. Indeed, we have held meetings with organizations with the hopes of working together on research projects that have not come to fruition due to a lack of readiness and interest on the part 
of all members of the community partner. Developing a productive research collaboration will be very difficult if a partner organization does not see the value of research and is not interested in embedding it in its process. Relatedly, a bourgeoning area of community-based research focuses on assessing community partners' readiness for engaging in the delivery and evaluation of clinical programs (Andrews et al., 2020). Engaging in an open discussion about readiness at the outset of establishing a research partnership is critical for laying the groundwork for a mutually beneficial partnership.

\section{What is the Social Position of my Research Team as it Relates to the Community Partner We} Would like to Engage?

A well-documented challenge in community-based research is the power differential between researchers and communities (Campano et al., 2015). Community-based research is frequently undertaken with community partners who represent or deliver services to equityseeking or marginalized groups. Indeed, an important goal of community-based research has been to redistribute intellectual power, authority, and decision-making within the research process. Therefore, the researcher and research team must consider their power and privilege as academics and redistribute power to the community partner. Consideration of power and privilege can take many forms, including team discussions, role acknowledgment, and selfreflection. Acknowledging that academic institutions have traditionally disseminated and shared knowledge in a "top-down" approach without considering community partners' perspectives is also critical. It may also be important to acknowledge the harm or lack of relational safety that has previously existed between members of academic institutions and community partners, particularly in Indigenous communities. 
Strategies that may help to mitigate power dynamics include soliciting and valuing the views and opinions of community partners, investigating partner-driven questions, codisseminating research findings, conducting research that benefits the community partner directly, transparency of the research process, and shared data ownership and access (Campano et al., 2015). For example, in our collaboration with the Child Abuse Service, at the outset of each new project, we hold meetings with the entire team of clinicians and staff to understand their research needs and the types of questions that would be most useful to their practice. We have conducted qualitative focus groups to understand the needs of both staff and clients. We have intentionally prioritized the research interests of the staff as the first questions we answer in a project to build buy-in and demonstrate that their engagement and opinion are important to our research team. We have put our research interests aside to prioritize the partner's pressing research question at several points in the research process.

\section{Are Members of the Research Team Insiders or Outsiders in the Research?}

It is important to note that considering one's position, power, and social location when engaging in community-based research projects is an ongoing process. A researcher needs to constantly reflect on how their own life experiences and worldviews may differ from their collaborators. Researchers need to consider where they position themselves on the "insideroutsider continuum" concerning the work of their community partner (Kerstetter, 2012). Specifically, researchers should consider whether they belong or are part of the communities they are conducting research in or whether they are positioned outside this group. For example, in working closely with clinicians at the Child Abuse Service, it was helpful that members of the research team were clinicians themselves and had worked in clinical environments with children and families who were maltreated. Thus, to staff, the researchers were in some ways considered 
insiders. Similarly, Breaking the Cycle has a clinical staff member with designated time allotted in their role to lead and conduct research. Having someone on the clinical team also be a leading member of the research team (Motz) helped build trust and make the research team feel like “insiders".

It is essential to consider how the multiple identities of members of the research team (i.e., gender, sexual orientation, cultural, racial/ethnic, and educational background) may interface with those of community partners and the clients they serve (Muhammad et al., 2015). Being an outsider does not preclude developing a potential research partnership but being aware and mindful of this position is critical. For example, a researcher with the interest and capacity to form a relationship with a community and who is open to learning new perspectives can be an effective co-creator in the research process.

Can the Researcher Follow the Lead of the Community Partner to Answer Questions of

\section{Shared Interest?}

From a research perspective, after considering whether there is a shared interest in developing a research partnership and self-reflecting on whether the research team can engage in a humble-relational approach, it is important to consider whether the research team is willing to ask questions that are of importance and relevance to the community partner. Pursuing partnerdriven questions is at the centre of community-based research and these questions should dovetail with the researcher's interests. For example, clinicians at the Child Abuse Service were interested in understanding the characteristics of children and families who accessed and completed trauma treatment. These questions were in line with the research expertise and interests of the researchers and provided an opportunity to fill clinically relevant research gaps in the literature. As developmental and intervention scientists, we were interested in understanding 
what interventions worked for which individuals and under what conditions. When we shared these ideas with the research team, they were excited and built on ways that we might be able to approach these questions from a feasibility standpoint.

\section{Is the Community Partnership Environment Stable and Sustainable?}

At the outset of establishing a research collaboration, it is vital to discern the feasibility of answering the research questions and completing the research project. There are many key questions that researchers may ask themselves that can help to inform their decision-making process (See Table 1). First, it is important to consider whether a community partner provides an environmentally stable and safe entity to conduct the research. Specifically, knowing if the partner is well established with secured or sustainable funding for the near future. It would be unfortunate to embark on projects with community-based partners only for the program or organization to shut down, and all potential for collaboration or data collection be lost. Of course, very few programs that offer services to marginalized populations have long-term and secure funding; however, it is crucial to consider the relative risk of engaging in this collaboration to both the researcher and the community partner. For instance, the disruption or resources required for short-term research may not be worthwhile. Alternatively, engaging in research may help a less financially stable program acquire and secure future funding.

\section{Will the Community Partner be Welcoming and Integrate Research Students and Staff?}

Researchers should identify whether the community partner would welcome research staff and students, often the engine and the heart of community-based research projects. Similarly, the researcher should consider what practices could support the integration of students and whether they have relational or financial resources that could support the student in the community setting. In our experience, research partnerships that have included students, 
integrated them as part of their programs at the outset, and shared their knowledge, have been fruitful both for the partners and the students. Community partners offer a rich and ecologically valid context for students to learn. Students who engage in community-based research often learn more from the community partner about relational engagement and systems thinking than from any academic course. On a practical level, ensuring that there would be physical space and infrastructure for the students and staff to conduct research is needed.

\section{Will it be Possible to Collect Data, and What Type of Data can be Collected?}

Researchers should also consider whether it will be possible to collect data that will satisfy the research methods they wish to employ (e.g., permission to do data collection, infrastructure for existing data collection). For example, we have met with potential partners where it became evident that we would be unable to collect any data as the information we were interested in and hoping to obtain was considered restricted, and therefore inaccessible. Thus, despite their desire to conduct research, the barriers to doing so were too great to overcome. It may also be the case that a research method (i.e., conducting neuro-imaging or videotaped interactions) would not be feasible or ethical to use. At this point, the researcher can decide whether they are willing to use alternate methods (e.g., qualitative interviews with staff, retrospective file review) or whether a community-based partnership is not the ideal approach for answering their research question.

Will it be Feasible to Obtain Research Ethics Approval, and Will This Project be Eligible for Funding Opportunities or Grants?

More than simply considering whether or not a project would receive ethics approval, it is critical to consider whether a project will "do no harm". Harm in the context of communitybased research can include re-traumatizing participants, reducing the trust participants have in 
systems, lack of transparency and honesty with community partners, and taking knowledge or information without permission in the absence of a collaborative and co-creative process. It is essential to consider these factors prior to formalizing a research partnership.

Additionally, given that an important criterion in academic evaluation is acquiring funding and generating knowledge outputs, a researcher should consider whether the project they will embark on can receive research funding to support research staff and students, and facilitate the dissemination of presentations, reports, or research publications. Whether the community partner can contribute time and in-kind resources (e.g., desk space, computer) is also worth considering. These contributions can demonstrate investment on behalf of the partner to funding agencies, increasing the likelihood of a successful application.

Taken together, there are several considerations for researchers before engaging in community-based research. Establishing a relationship with a community partner and obtaining answers to key questions requires time and commitment. Depending on the researcher's preexisting relationship with a partner and the insider/outsider status, it would not be unusual for the initial relationship development process to span several meetings over several months. While this research process unfolds over time, ensuring that the capacity of the research team and research match is in place can facilitate a strong foundation on which to build a program of research.

\section{Considerations for Community Partners}

Through collaborative discussion with our community partners, we elicited the considerations that may be important for community organizations when contemplating whether or not to engage in a collaborative project with researchers. Thus, the following section is informed by the perspectives and voices of our community partners (Cardinal, Hartwick, Leslie). A central consideration from the perspective of our community partners was the impact of 
research on the staff and clients served through the organization. Community organizations rightfully prioritize the clients they serve and their staff. Therefore, any research collaboration would need to "fit in" with the values and approaches used at the community organization. It is thus important for community partners to consider whether the collaboration with this specific research team, for this particular project, is the right fit for their organization. In Table 2, we summarize questions community partners may find helpful to ask themselves before agreeing to engage in a research collaboration.

\section{Is the Organization Interested in Conducting Research? Does Conducting Research Align with the Strategic Goals and Needs of the Organization?}

A critical question for a community organization is whether there is readiness and interest to conduct research. This readiness can be evaluated not only at the level of senior management but at the level of individual staff (Andrews et al., 2020). Specifically, it is important to consider whether conducting research aligns with the strategic goals and needs of the organization. For the community organizations included in the current paper, conducting research was in line with the intent to provide the best evidence-informed services to their clients. For example, program evaluation and research were considered and embedded within Breaking the Cycle since its inception in 1995. There was an understanding that research would help staff better understand the needs of their clients and inform future program development. It may be helpful for an organization to consider the benefits of conducting research. For example, at the Child Abuse Service, clinicians recognized that conducting research would provide valuable information that could improve their clinical service delivery. Staff also had the aspiration of sharing some of the innovative clinical methodologies they were using and had limited time to engage in research or writing. The team at the Child Abuse Service viewed the research collaboration as a way to 
disseminate and share the knowledge they were acquiring as part of their practice. They also felt that conducting research helped to address external pressures and demands to provide evidencebased services.

\section{Do the Researcher's Values, Approach, and Belief System Align with Those of the}

\section{Organization?}

When community partners consider whether to engage in a research partnership, it is helpful to evaluate whether the researcher's approach and values match those of the community organization. A research collaborator who takes the time to listen, genuinely understands the partner agency, and prioritizes the needs of the partner agency, likely possesses the skills to maintain a mutually beneficial partnership over time. For example, the Child Abuse Service staff have noted that they value a research team that is willing to be flexible, prioritize their research interests, and develop a strong working relationship to help make the research process motivating and meaningful. An unwillingness to be flexible on the part of researchers should alert community partners to other future difficulties that could emerge.

What is the Burden of Conducting the Research on Staff? Is Conducting the Research Safe, Ethical, and Feasible with the Community Partner's Client Population?

One of the first considerations that come to mind for community organizations before engaging in collaborative research is the implications for the workload of staff and the burden on clients. Regarding staff workload, a leading concern of staff regarding participating in research is whether this will add additional time or load to the team already managing immense workloads. For example, in starting a new research process that required clinical staff to obtain participant consent, clinicians at the Child Abuse Service were concerned about the additional time required. 
A second concern is the potential burden that the proposed research may have on the clients or participants. Researchers must be willing to take a trauma-informed approach to the research process (Singh et al., 2020). That is, many members of marginalized groups may have had past experiences that limit trust with the systems and institutions researchers belong to. For example, at Breaking the Cycle, where most clients have histories of severe trauma and abuse, the importance of conducting research that does not re-traumatize clients is paramount. Thus, BTC has been very discerning in the research projects it has engaged in and ensures that clinicians are part of the data collection process to act as a supportive presence.

\section{Is There a Staff Member within the Community Partner Organization that can Lead,} Champion, and Act as a Liaison for the Research Process?

Another crucial component for a successful community-research partnership is a research lead or champion within the organization who can act as a liaison between the researchers and the community organization. In addition to being the "go-to" person for the researchers, this person serves as a communicator between members of the community organization and the researchers. The champion is essential to the success of the research. For example, at the Canadian Red Cross, Shelley Cardinal, National Indigenous Advisor, was the driving force behind the research evaluation of a violence prevention education program for Indigenous communities. Her role was integral in establishing and executing the research partnership as she bridged the relationship between researchers who were outsiders to the Indigenous community. Do We have Resources to Contribute to the Research (i.e., in-kind time, space)?

Lastly, before embarking on a community-based research partnership, community partners should identify whether they have resources to contribute as part of the collaboration. Understandably, many government-funded community organizations and not-for-profit 
organizations have limited funding and small budgets. However, if organizations value and prioritize research and evaluation, contributing in-kind support through staff time or space demonstrates a shared commitment to the project. Mutual investment by both the community partner and the research team is often needed or required in applications to external funding opportunities.

\section{Challenges to Community-Based Research}

While there are certainly many benefits to community-based research, we would be remiss if we did not point that there can be challenges and stumbling blocks along the way as well. Community-based research can be more time-consuming and often unfolds in less tidy ways than research conducted in the controlled environment of a laboratory (Pepler, 2016). Community-based research occurs within larger systems (e.g., community organizations, healthcare systems, and education systems) that have several moving parts that are all interacting, making for a complex and sometimes extended research process. Challenges can arise at different levels of the system, including at the level of the research team, among individual members of the community partner organization, in relationships both within and between researchers and community partners, and at the broader system level (e.g., leadership level, funding climate, political climate). Below we detail some research challenges that have been identified in our experience conducting community-based research. We also offer some points of reflection for how we addressed and/or overcame these barriers.

\section{Integrating Research in the Clinical Setting}

While some community partners plan for and envision incorporating research as part of their service delivery from the outset (e.g., Breaking the Cycle), this is generally the exception rather than the rule. More often than not, researchers may enter an environment that has not 
necessarily planned or integrated evaluation or research components before. It is often necessary to understand the organization's clinical service flow and process to know how research might be best integrated. This is where it is critical to be flexible and creative in considering measurement methods and start with smaller realistic projects before moving on to larger-scale projects. For example, when we began our research collaboration with the Child Abuse Service, there had previously been limited integration of research and clinical work. We started by conducting a retrospective file review because this method allowed us to systematically obtain data that could be analyzed without overburdening staff and clients. This also allowed the clinical team and researchers to develop a relationship and for the researchers to learn about the clinical flow and process by reading case files.

Now, several years after completing our first project, we have integrated an electronic data collection process that gathers data directly rather than relying on a file review methodology. As part of this approach, the clinical team and researchers jointly selected standardized measures that would be clinically informative and could also be used for research purposes. This shared decision-making process was critical for clinicians to use the new data capture system. In our experience, when research is fully integrated as part of clinical practice, clients have the same experience, complete the same questionnaires, and receive the same service regardless of whether they are engaging in research or not. This decreases client burden to participate in research and increases the likelihood of recruiting a representative sample of participants. Similarly, clinicians follow the same process and follow the same workflow whether their client consents to participate in research or not. Although the integration of research within a clinical setting takes time, learning, and relational development, the outcome is 
highly clinically relevant data with the opportunity to inform changes and improvements in practice.

\section{Establishing and Retaining Staff Engagement}

One challenge that we have encountered in some of our collaborations is establishing buy-in from staff that conducting research as part of their clinical practice is worthwhile. There has been apprehension or concern from the team that integrating research may add additional work or burden to an already demanding workload. In our experience, it is imperative to consider these concerns for the research partnership to be successful. Through meetings and soliciting feedback, it can be important for staff to have the opportunity to share their perspectives and be heard. In our experience, we have found it helpful to develop processes that minimize staff burden and perhaps even reduce their workload. For example, by implementing different data collection tools, we have been able to eliminate the scoring of various assessment measures that are now scored electronically as part of the research process at the Child Abuse Service. By reducing the time-consuming nature of the research, the staff is more likely to be engaged and willing to participate in the research process. We have also found it helpful to pilot changes with a small group of clinicians, who can provide feedback and help with troubleshooting, prior to system-wide implementations or changes.

\section{Minimizing the Research Burden to Clients}

All community partners we have worked with have highlighted the burden of research on clients as a challenge to conducting research. Researchers can often have unrealistic expectations about the demands of participating in the research process. For example, completing questionnaires that would not directly inform clinical service, are not sensitive to the needs of the client, and/or engaging in a research paradigm that would not otherwise be required are 
limitations. In all of our collaborative research projects, we have put the needs of clients first and have followed the lead of the partner organization with regards to how the research can minimize the burden to clients. This approach requires researchers to be selective and thoughtful about what demands of participants are genuinely integral to the research project.

\section{The Pace of the Research Process}

As we have mentioned previously, community-based research can be more timeconsuming and requires a deeper level of relational development and problem solving than other forms of research. This means that the timelines for community-based projects often need to be adjusted or extended to accommodate for unforeseen barriers or roadblocks (D'Alonzo, 2010)., We set joint timelines with the partners and ensure that the scope of projects is feasible within that timeline to ensure goals can be achieved in a timely manner to help maintain energy and enthusiasm for the project. Another strategy we use to help keep research projects on track is having research assistants embedded within the community setting. For example, research assistants and graduate students at Breaking the Cycle are physically embedded within the clinical program. Research staff share space with clinical staff, attend clinical meetings and seminars, eat lunch with clinical staff, and participate in center-wide celebrations and activities. Embedded research and clinical staff facilitates relationships that promote collaboration and shared goals that enable the research process.

\section{Leadership, Funding, and Program Changes}

Community-based partners often include large non-for-profit organizations, governmentfunded organizations, or donor-funded organizations. Challenges can arise when changes in leadership, funding, or program structures occur during the research process. This can be especially problematic if new leadership is less supportive of research or funding has been cut so 
that it is no longer feasible to conduct the research in the same way. Although our research teams have not experienced drastic cuts to funding or program changes, we have experienced shifts in leadership. We have found it critical at such junctures to connect with new leaders and provide them with the co-developed projects goals and the research conducted to date. It is important to consider from the outset of a project that these shifts may occur and include safeguards against knowledge loss, such as documentation of processes and procedures.

\section{Successes in Community-Based Research}

While we identified several challenges that can occur in the context of community-based research, the positive outcomes associated with conducting research that is collaborative and community-engaged far outweigh the drawbacks. First, at the centre of community-based research is developing long-term and positive relationships with colleagues outside our typical circle of influence. In our experience, the relationships that have developed through our community-based research partnerships have been career-long friendships that have made the research endeavour a pleasure to undertake. Within community-based research, sharing ideas and co-creation of knowledge also creates a stimulating research environment for both researchers and the community partner. Enthusiasm about the collective work and celebrating shared accomplishments results in shared meaning-making that is difficult to replicate in other settings.

Second, there is a higher likelihood of uptake for research that is highly clinically relevant and directly informs clinical practice. Indeed, previous research has demonstrated that exporting researcher-developed interventions into community clinical practice is challenging (Toth \& Manly, 2011). Community partners are often using and engaging in evidence-based practices that can inform researchers' understanding of what works, under what circumstances, for a specific population. By engaging in community-based research, the sharing and co-creation 
of knowledge accelerate the timelines for expertise to be mobilized into practice. For example, research at Breaking the Cycle in the early 2000s helped to identify interpersonal violence as an important determinant in the lives of substance-using women and their young children. As such, Breaking the Cycle developed Connections, an interpersonal violence group intervention for mothers with young children. (Mothercraft Press, 2014). Thus, a potential benefit of research for community partners is in demonstrating the effectiveness of the services provided and being identified as a source of knowledge creation and mobilization. For example, Breaking the Cycle has been recognized as a leader in knowledge creation and mobilization related to programs and services for substance-using mothers and their young children. The collaborative research at Breaking the Cycle has been documented in multiple publications and reports (e.g., (Motz et al., 2006; Motz, 2020; Pepler et al., 2014; Pepler et al., 2002) and disseminated nationally and internationally.

Third, research that is conducted within community organizations can also lead to essential changes in practice. For example, research at the Child Abuse Service helped identify key factors in predicting successful treatment completion for children and youth who have been maltreated, including supportive caregiver involvement and engagement in treatment (Eirich et al., 2020). After sharing the findings with the clinical team, they began placing an increased emphasis on inclusion and participation of parents and caregivers as part of child trauma treatment has been rapidly implemented. The co-creation of research with community partners increased the likelihood that research knowledge was adopted in practice.

Fourth, community-based research provides a unique opportunity to test and understand the mechanism by which change occurs within a highly ecologically valid context. Psychological researchers want to know how changes in mental health occur (i.e., to whom, under what 
circumstances, and when). Community-based research provides the opportunity to answer these fundamental questions that would be nearly impossible to observe in a laboratory-based environment. Community-based research necessitates that researchers be embedded in the ecological context, providing ample opportunity for qualitative and observational insight. For example, by conducting research at Breaking the Cycle, we have understood that improvements in the parent-child relationship are primary mechanisms by which child development and maternal outcomes are improved through early intervention (Espinet et al., 2016). The research findings mirrored what staff at the centre had been hypothesizing since the program's inception: relationships were central to the process of healing from trauma and addiction. Taken together, community-based research can provide a unique opportunity to shed light on how psychological change manifests and to mobilize these findings rapidly.

Lastly, a collaborative and successful community-based research partnership can be a catalyst for obtaining research funding and disseminating scholarly research outputs. For example, several funding agencies now require community partners, patients, knowledge-users, or stakeholders to participate in the research project. These requirements are in line with research practices that are both informed by and targeted towards end-users. Additionally, our experience has been that community-based research can lead to innovative research outputs. While creativity and flexibility are often required, important scientific questions can be answered at the interface of science and practice.

\section{Future Directions for Community-Based Research in Canadian Psychology}

As we reflect on our learnings from engaging in community-based research, it is clear that efforts to promote community-based research in Canada are needed. While communityengaged research is theoretically a priority for Canadian academic institutions, tangible steps 
need to be taken to increase the uptake of community-based research in Canadian psychology. Bolstering and increasing community-based research in Canada includes practical experiences and training in community-based approaches for students, imagining and creating roles for psychologists within community organizations, increased incentives and recognition of community-based research in the academic sphere, and increased funding mechanisms for research with communities.

\section{Imagining, Creating, and Advocating for Different Roles for Graduate School Trained}

\section{Psychologists}

One of our learnings is the importance of having a champion, liaison, or "critical bridge person" within the community partner (Barnes et al., 2009). Ideally, this individual is embedded within the community organization and has sufficient research knowledge and literacy to co-lead the research process. This person is invaluable in forging a long-term relationship between the community organization and the research team and plays a vital role in the execution of the research project. Additionally, this person can play an essential role in building research capacity within the community organization, rather than sourcing it from outside. Graduates from doctoral psychology programs are ideally trained and positioned for these roles. They possess innumerable skills that can be used in community organizations, including systems thinking, program evaluation, data analysis, teaching, critical literature review, and project management skills. Thus, an important future direction for the growth of these roles for psychology graduates includes advocacy by psychologists in the field and within the academic sphere (Cohen et al., 2012). For example, as demands increase for evidence-based programs and service delivery, the expertise and research knowledge that psychologists bring should place them at the forefront of hiring candidates. Increased advocacy for the development of these roles and employment 
opportunities will benefit the profession of psychology and have the potential to accelerate the effectiveness of community-based service provision.

\section{Incentives and Recognition of Community-Based Research in the Academic Sphere}

Successfully engaging in community-based research requires heavy lifting, such as relationship development and partnership formation, that are not required in basic or laboratory research. While we outlined the benefits of CBPR, it is important to note that this research method can be more time-consuming, less linear, and can result in different scholarly outputs than those traditionally valued in academia. As such, to promote engaging in community-based research, academic institutions should consider implementing practices that ensure that the effort required to conduct this work is recognized. For example, it has been suggested that the development of community-based research centers, community-based research-oriented faculty appointments, and allocating specific resources for community-based research, as well as the modification of tenure and promotion guidelines, are all potential change opportunities (Nyden, 2003). Specifically, considering the impact and mobilization of knowledge (i.e., what practices changed based on this research or how was the quality of life improved for community members based on this work?), not simply the number of publications or grants received. In line with a growing emphasis on social innovation and social impact, several academic institutions have developed knowledge and community-engagement offices that aim to connect researchers with community partners, to help build collaborative partners and create knowledge with impact beyond the academic sphere. For example, the University of Calgary has recently developed a Knowledge Engagement team to support partnership formation, research collaboration, knowledge mobilization, and building capacity to conduct community-based research (Calgary, 2021). Many institutions now also have awards and recognitions for faculty and students who 
show excellence and impact when conducting research beyond the academic sphere. As academic institutions start to include community engagement as a strategic direction, this vision must be backed up by funding opportunities, recognition, and rewards to promote its growth.

It is also essential to recognize that knowledge creation and dissemination occur outside the academic sphere within the community. Often referred to as "grey literature" in scholarly circles (e.g., policy documents, working papers, reports, newsletters), an important direction is to value these outlets' contributions and recognize their impact from a knowledge mobilization perspective.

\section{Increased Funding Mechanisms for Community-Based Research}

There are several existing funding opportunities through the tri-council funding agencies that target the development and engagement of community partners and patients in research. While these opportunities are likely contributing to the uptake and spurring of community-based research, various funding opportunities from different institutions and organizations continue to be needed. Additionally, funding opportunities for community-based research may need to consider how the process, output, reporting, and assessment of readiness for the project may need to be different for CBPR-related projects (Tendulkar et al., 2011). For example, changes in timelines and shifts in how the research unfolds are all par for the course in community-based research. Funding opportunities that allow increased flexibility and understanding in this regard would be beneficial.

\section{Training Students for Working in Community Settings}

Preparing students to engage in community-based research should be included in graduate school training in psychology in Canada. Yet only $40 \%$ of psychology departments in Canada offer courses in community psychology. Additionally, it is estimated that approximately 
$35 \%$ of graduate students seeking academic positions will be unable to gain a position (VottaBleeker \& Cohen, 2014), suggesting that training for opportunities outside academia is needed for students graduating from doctoral psychology programs. In addition to course-based content in community-based research and program evaluation, students need hands-on learning opportunities that provide structured learning opportunities to see how embedded research is conducted (Stocking \& Cutforth, 2006). Courses that include a practicum component where students have the opportunity to test out and apply the theoretical knowledge learned in the classroom, and provide the opportunity to form relationships with community organizations are essential. Students also need the opportunity to observe community-based research in action, including learning about the self-reflection and humble-relational approach required to form trusting relationships with community partners. Pedagogical activities that help students develop these skills, such as role-play, experiential fieldwork, structured journaling, and guided group discussion, can help students learn to reflect on their social position and how to effectively engage in relationships with the community partners (Ross, 2010). Increased instruction in community-based research in psychology departments in Canada has the potential to equip the future generation of psychological researchers with the necessary skills to engage in and conduct translational research in the community.

\section{Conclusions}

One of the most significant social problems of our time is the increasing prevalence of mental health difficulties and the inadequate approaches and treatments to manage these difficulties effectively. Nearly $50 \%$ of Canadians will experience a mental health difficulty before 40 years of age (Smetanin et al., 2011), with almost one-third of individuals not receiving the mental health care they need (Sunderland \& Findlay, 2013). Top-down research conducted in 
the academic silo is insufficient for tackling these challenges as solutions must be discovered and co-created in the complex systems and environment in which they occur.

Based on our own experiences, we identify specific considerations from the perspective of researchers and community partners for engaging in community-based research, including relational capacity, readiness, research fit, and feasibility. Researchers need to be willing to enter these spaces and demonstrate the skills and humility that lead to an invitation to collaborate. Although community-based research requires more time, the willingness to develop relationships, flexibility, and a high level of problem-solving skills, the benefits for both researchers and community partners far outweigh the challenges.

The increase of community-based research in Canadian psychology will require a targeted and concerted effort in academic and community settings. The next generation of researchers need to acquire the skills and connections to engage in this work. Increased value needs to be placed on evidence-based service provision and program evaluation in the community setting. Ultimately, bridging the knowledge-to-practice gap in Canadian psychology is a joint effort and occurs when science and practice connect. True collaboration embeds research in the community, which allows for data extraction that is highly representative and knowledge transmission that is meaningful and impactful. The uptake of community-based research in Canada has the potential to accelerate both our understanding and solutions for complex social challenges. 
Table 1. Critical Questions for Researchers to Ask Themselves When Engaging in CommunityBased Research

Researcher Readiness and Capacities

- Is my research team capable of engaging in a positive, respectful, and humble relationship with a community partner?

- Is my research team willing to listen and prioritize the needs and questions of the community partner?

- Is the partner organization ready to engage in a partnership?

- What is the social position of my research team as it relates to the community partner we would like to engage?

- Are members of the research team insiders or outsiders in the research?

Research Match and Feasibility

- Can the researcher follow the lead of the community partner to answer questions of shared interest?

- Is the community partnership environment stable and sustainable?

- Will the community partner be welcoming and integrate research students and staff?

- Will it be possible to collect data, and what type of data can be collected?

- Will it be feasible to obtain research ethics approval to conduct the project?

- Is this the type of project that would be eligible for funding opportunities or grants?

- Will it be possible to conduct research with sufficient rigor to disseminate findings in the form of an academic presentation or publication? 
Table 2. Critical Questions for Community Partners to Ask Themselves When Engaging in Community-Based Research

Community Partner Interest and Readiness

- Is the organization interested in conducting research? Does conducting research align with strategic goals and needs as well as the culture of the organization?

- Will there be staff interest, support, and buy-in to conduct the research?

- Will conducting research benefit the organization or the services it provides in any way?

Match between Community Partner and Researcher

- Do the researchers have the capacity to develop a respectful, humble, and thoughtful relationship with the partner?

- Are the researchers individuals whose values, approach, and belief system aligned with those of the organization?

- Are the researchers interested in asking questions that align with the needs and goals of the partner and the clients they serve?

Research Feasibility

- What is the burden of conducting the research on staff?

- Is conducting the research safe, ethical, and feasible with the community partner's client population?

- Is there a staff member within the community partner organization that can lead, champion, and act as a liaison for the research process?

- Do we have resources to contribute to the research (i.e., in-kind time, space)? 


\section{References}

Andrews, N. C. Z., Motz, M., \& Pepler, D. J. (2020). Developing and testing a readiness tool for interpersonal violence prevention partnerships with community-based projects. Journal of Community Psychology, 48(6), 1715-1731. https://doi.org/10.1002/jcop.22361

Andrews, N. C. Z., Motz, M., \& Pepler, D. J. (2021). A national implementation of a community-based intervention for mothers experiencing violence in relationships. Journal of Family Psychology, 35(1), 92-102. https://doi.org/10.1037/fam0000810

Andrews, N. C. Z., Motz, M., Pepler, D. J., Jeong, J. J., \& Khoury, J. (2018). Engaging mothers with substance use issues and their children in early intervention: Understanding use of service and outcomes. Child Abuse and Neglect, 83, 10-20. https://doi.org/10.1016/j.chiabu.2018.06.011

Andrews, N. C. Z., Pepler, D., \& Motz, M. (2019). Research and evaluation with communitybased projects: Approaches, considerations, and strategies. American Journal of Evaluation, 40(4), 548-561. https://doi.org/10.1177/1098214019835821

Aubry, T., Sylvestre, J., \& Ecker, J. (2010). Community psychology training in Canada in the new millennium. . Canadian Psychology, 51(2), 89-95.

Barnes, J., Altimare, E., Farrell, P., Brown, R., Burnett, R. C., Gamble, L., \& Davis, J. (2009). Creating and Sustaining Authentic Partnerships with Community in a Systemic Model. Journal of Higher Education Outreach and Engagement, 13(4), 15.

Bondi, B. C., Pepler, D. J., Motz, M., \& Andrews, N. C. Z. (2020). Establishing clinically and theoretically grounded cross-domain cumulative risk and protection scores in sibling groups exposed prenatally to substances. Child Abuse and Neglect, 108, 104631. https://doi.org/10.1016/j.chiabu.2020.104631 
Campano, G., Ghiso, M. P., \& Welch, B. J. (2015). Ethical and professional norms in community-based research. . Harvard Educational Review, 85, 29-49. https://doi.org/doi:10.17763/haer.85.1.a34748522021115m

Cardinal, S. \& Pepler, D. (2021). Community journey of change through relational determinants of health. The International IIndigenous Policy Journal, 12(3), 1-16.

Cohen, K. R., Lee, C. M., \& Mcllwraith, R. (2012). The psychology of advocacy and the advocacy of psychology. Canadian Psychology/Psychologie Canadienne,, 53(3), 151158. https://doi.org/ https://doi.org/10.1037/a0027823

Corburn, J. (2005). Street Science: Community Knowledge and Environmental Health Justice. MIT Press.

Craig, S., Bondi, B. C., Diplock, B., \& Pepler, D. J. (2021). Building Effective Research-Clinical Collaborations in Child, Youth, and Family Mental Health: A Developmental-Relational Model of Co-Creation. Journal of Therapeutic Schools and Programs, XIII, 103-131.

Crooks, C. V., Exner-Cortens, D., Siebold, W., Moore, K., Grassgreen, L., Owen, P., Rausch, A., \& Rosier, M. (2018). The role of relationships in collaborative partnership success: Lessons from the Alaska Fourth R project. Evaluation and Program Planning, 67, 97104. https://doi.org/10.1016/j.evalprogplan.2017.12.007

D'Alonzo, K. (2010). Getting started in CBPR: lessons in building community partnerships for new researchers. Nursing Inquiry, 17(4), 282-288.

Eirich, R., Racine, N., Garfinkel, D., Dimitropoulos, G., \& Madigan, S. (2020). Risk and protective factors for treatment dropout in a child maltreatment population. Adversity and Resilience Science, 1(165-177). 
Espinet, S., Motz, M., Jeong, J. J., Jeenkins, J., \& Pepler, D. J. (2016). 'Breaking the Cycle’ of maternal substance use through relationships: a comparison of integrated approaches. . Addiction Research \& Theory, 24(375-388).

Gearing, R. E., Mian, I. A., Barber, J., \& Ickowicz, A. (2006). A methodology for conducting retrospective chart review research in child and adolescent psychiatry. Journal of the Canadian Academy of Child Adolescent Psychiatry, 15(3), 126-134. https://www.ncbi.nlm.nih.gov/pubmed/18392182

Hacker, K. (2013). Community-based participatory research. Sage Publishers.

Kazdin, A. (2016). Closing the research-practice hap: How, why, and whether. Clinical, Psychology, Science, and Practice, 23(2), 201-206.

Kerstetter, K. (2012). Insider, Outsider, or Somewhere Between: The Impact of Researchers' Identities on the Community-Based Research Process. Journal of Rural Social Sciences, 27. https://egrove.olemiss.edu/jrss/vol27/iss $2 / 7$

Koster, R., Baccar, K., \& Lemelin, R. (2012). Moving from research ON, to research WITH and FOR Indigenoous communities: A critical reflection on community-based participatory research. The Canadian Geographer, 56(2), 195-210.

Mothercraft Press (2014). Connections: A group intervention for mothers and children experiencing violence in relationships.

McHugh, K., \& Barlow, D. (2012). The reach of evidence-based psychological interventions. In K. McHugh \& D. Barlow (Eds.), Dissemination and implementation of evidence-based psychological interventions. Oxford University Press. 
Minden, K. (2021). Still waiting for accountability on youth mental illness: Karen Minden for Inside Policy. https://www.macdonaldlaurier.ca/still-waiting-accountability-youthmental-illness-karen-minden-inside-policy/

Morris, Z. S., Wooding, S., \& Grant, J. (2011). The answer is 17 years, what is the question: understanding time lags in translational research. Journal of the Royal Society fo Medicine, 104(12), 510-520. https://doi.org/10.1258/jrsm.2011.110180

Motz, M., Andrews, N. C. Z., Bondi, B. C., Leslie, M., \& Pepler, D. J. (2019). Addressing the impact of interpersonal violence in women who struggle with substance use through developmental-relational strategies in a community program. International Journal of Environmental Ressearch and Public Health, 16(21). https://doi.org/10.3390/ijerph16214197

Motz, M., Leslie, M., Pepler, D. J., Moore, T. E., \& Freeman, P. A. (2006). Breaking the cycle: measures pf progress 1995- 2005. . Journal of FAS Interenational, 4, e22.

Motz, M., Reynolds, W., Leslie, M. (2020). The Breaking the Cycle compendium volume 2 Healing through relationships. Mothercraft Press

Muhammad, M., Wallerstein, N., Sussman, A. L., Avila, M., Belone, L., \& B., D. (2015). Reflections on researcher identity and power: The impact of positionality on community based participatory research (CBPR) processes and outcomes. Critical Sociology, 41(78), 1045-1063. https://doi.org/10.1177/0896920513516025

Nyden, P. (2003). Academic incentives for faculty participation in community-based participatory research. Journal of General Internal Medicine, 18, 576-585.

Pepler, D. (2016). Stepping sideways to move forward: Closing the science-practice gap. . Canadian Psychology, 57(1), 44-50. 
Pepler, D., Motz, M., Leslie, M., Jenkins, J., Espinet, S., \& Reynolds, W. (2014). The motherchild study: Evaluating treatment for substance-using women.

Pepler, D., \& Rubin-Vaughan, A. (2011). Walking the prevention circle: A report for the National Criime Prevention Centre. Prepared for the Canadian Red Cross RespectED Programs.

Pepler, D. J., Moore, T. E., Motz, M. H., \& Leslie, M. (2002). Breaking the cycle: The evaluation report (1995-2000).

Mothercraft Press (2014). Connections: A group intervention for mothers and children experiencing violence in relationships.

Racine, N., Dimitropoulos, G., Hartwick, C., Eirich, R., van Roessel, L., \& Madigan, S. (2021). Characteristics and service needs of maltreated children referred for mental health services at a child advocacy centre in Canada. Journal of the Canadian Academy of Child and Adolescent Psychiatry, 30(2), 92-103. https://www.ncbi.nlm.nih.gov/pubmed/33953761

Racine, N., Eirich, R., Dimitropoulos, G., Hartwick, C., \& Madigan, S. (2020). Development of trauma symptoms following adversity in childhood: The moderating role of protective factors. Child Abuse and Neglect, 101, 104375. https://doi.org/10.1016/j.chiabu.2020.104375

Racine, N., Hartwick, C., Collin-Vezina, D., \& Madigan, S. (2020). Telemental health for child trauma treatment during and post-COVID-19: Limitations and considerations. Child Abuse Negl, 110(Pt 2), 104698. https://doi.org/10.1016/j.chiabu.2020.104698

Rawat, S., \& Meena, S. (2014). Publish or perish: Where are we heading? Journal of Research in Medical Science, 19(2), 87-89. https://www.ncbi.nlm.nih.gov/pubmed/24778659 
Ricard, D.-L., Pepler, D., \& Cardinal, S. (2021). A starting place story for the self-determined community journey of change. Paper in preparation, York University.

Riddell, J., Salamanca, A., Pepler, D., Cardinal, S., \& McIvor, O. (2017). Laying the groundwork: A practical guide for ethical research with Indigenous communities. International Indigenous Policy Journal, 8(2).

Ross, L. (2010). Notes from the field: Learning cultural humility through critical incidents and central challenges in community-based participatory research. Journal of Community Practice, 18(2-3), 315-335.

Singh, C. D., Andrews, N. C. Z., Motz, M., Pepler, D. J., Leslie, M., \& Zuberi, S. (2020). Trauma-informed and relational approaches to service provision: building communitybased project capacity to respond to interpersonal violence through a national initiative. BMC Public Health, 20(1), 1833. https://doi.org/10.1186/s12889-020-09960-3

Skipper, Y., \& Pepler, D. J. (2020). Stepping into interdependent and relational space using cocreation. Action Research, 1-18.

Smetanin, P., Stiff, D., Briante, C., Adair, C. E., Ahmad, S., \& Khan, M. (2011). The life and economic impact of major mental illnesses in Canada: 2011 to 2041. .

Stocking, V., \& Cutforth, N. (2006). Managing the challenges of teaching community-based research courses: Insights from two instructors. Michigan Journal of Community Service Learning, 13(1), 56-65.

Sunderland, A., \& Findlay, L. (2013). Perceived need for mental health care in Canada: Results from the 2012 Canadian Community Health Survey - Mental Health. 
Tendulkar, S. A., Chu, J., Opp, J., Geller, A., Digirolamo, A., Gandelman, E., Grullon, M., Patil, P., King, S., \& Hacker, K. (2011). A funding initiative for community-based participatory research: Lessons from the Harvard Catalyst Seed Grants. Progress in Community Health Partnerships: Research, Education, and Action, 5(1), 35-44.

https://doi.org/https://doi.org/10.1353/cpr.2011.0005

Toth, S. L., \& Manly, J. T. (2011). Bridging research and practice: challenges and successes in implementing evidence-based preventive intervention strategies for child maltreatment. Child Abuse and Neglect, 35(8), 633-636. https://doi.org/10.1016/j.chiabu.2011.05.003

University of Calgary (2021). Knowledge Engagement. Retrieved September 8th, 2021 from https://research.ucalgary.ca/engage-research/knowledge-engagement

Votta-Bleeker, L., \& Cohen, K. R. (2014). Matching need, supply, and demand in psychology: How many to do what for whom? . Canadian Psychology/Psychologie Canadienne, 55(2), 131-134. https://doi.org/https://doi.org/10.1037/a0036456

Wallerstein, N., \& Duran, B. (2006). Using community-based participatory research to address health disparities. Health Promotion Practice, 7(3), 312-323. 